\title{
An investigation on the effects of financial management skills, wealth and financial intelligence on investors' risk tolerance: Empirical evidence from Tehran Stock Exchange
}

\author{
Saied Aghasi ${ }^{\mathrm{a}}$, Mohammad Reza Dalvi ${ }^{\mathrm{a}}$ and Sahar Biglari ${ }^{\mathrm{b}}$
}

\section{H R O N I C L E}

\section{Article history:} \\ Received 5 January 2014 \\ Received in revised format \\ 8 March 2014 \\ Accepted 11 March 2014 \\ Available online \\ 12 March 2014 \\ Keywords: \\ Tehran Stock Exchange \\ Financial management skills \\ Wealth \\ Financial intelligence
}

${ }^{a}$ Assistant Professor, Department of Public Administration, Dehaghan Branch, Islamic Azad University, Esfahan

${ }^{b}$ M.A Student, Department of Public Administration, Islamic Azad University, Dehaghan Branch, Esfahan, Iran

\section{A B S T R A C T}

During the past few years, Tehran Stock Exchange (TSE) has been changed into one of the most popular places to invest and index has been quadrupled in fewer than three years. As a result, many people have been attracted to invest on TSE market. This paper presents an empirical investigation to study the effects of investors' personal characteristics including financial management skills, wealth and financial intelligence on investors' risk tolerance among 384 randomly chosen investors who were active on TSE market in city of Esfahan, Iran. Using structural equation modeling, the study has determined that financial management skills, wealth and financial intelligence influence positively on investors' risk tolerance.

\section{Introduction}

For years, stock market has been considered as a good source for investment opportunities and many retain and big investors look for investment in various firms by buying the shares of the firms on stock exchange (Lusardi et al., 2007; Chorafas, 2011). Some stock exchange such as New York Stock Exchange (NYSE) and Nasdaq Stock exchange are considered as a primary source of investment for big financial institutions. Tehran Stock Exchange (TSE) has been one of the primary sources of investment for many Iranian people. The stock exchange has attracted many retail investors during the past few years since the whole stock exchange has been quadrupled in just fewer than three years. Pham et al. (2012) investigated the effect of financial management practices and financial behaviors on the relationship between materialism and compulsive buying. They reported that financial attitudes and financial management practices could moderate the relationship between materialism and compulsive buying. In their survey, financial management practices and not financial *Corresponding author.

E-mail addresses: sajadmalek88@yahoo.com (S. Biglari) 
attitudes, substantially forecasted compulsive buying severity after controlling for materialism. Besides, financial management practices moderated the relationship between materialism and compulsive buying severity. The findings supported the inclusion of financial management components in current psychosocial interventions and stated that highly materialistic individuals with poor financial management practices were particularly prone to compulsive buying problems. Yao et al. (2011) applied an analytical technique to separate the effects of personal characteristics such as age on financial risk tolerance and reported that aging and period influenced on financial risk tolerance.

Yao and Curl (2011) applied the 1992-2006 waves of the Health and Retirement Study (HRS) to study changes in risk tolerance levels over time in response to stock market returns. They reported that risk tolerance could increase when market returns increase and it could reduce when market returns reduce. Investors who change their risk tolerance accordingly are more likely to invest in stocks when prices are high and sell when prices are low. Therefore, investors must be informed to overcome the bias of overweighting recent news of market performance. Investors' personal characteristics must be investigated in early stages (Van Rooij et al., 2007, 2011). Durrani and Tariq (2012), for instance, explored the impact and importance of numeracy skills in graduate recruitment within a diversity of employment sectors.

Millo and MacKenzie (2009) reported that the remarkable success of today's financial risk management methods have to be attributed primarily to their communicative and organizational usefulness and less to the precision of the results they generated. They traced the intertwined historical paths of financial risk management and financial derivatives markets and analyzed the social, political and organizational factors that underpinned the exponential success of one of today's leading risk management methodologies, the applications based on the Black-Scholes-Merton options pricing model. They found that, the events in the aftermath of the market crash of October 1987 indicated that the practical usefulness of financial risk management methods overshadowed the fact that when financial risk management was critically required the risk model was inaccurate.

Finke and Huston (2003) investigated the relationship between net worth and net financial assets and risk tolerance based on the data from the 1998 Survey of Consumer Finances. Willingness to take financial risk was related to a substantially higher net worth for the whole sample, and for samples within age groups.

Altman (2012) performed an investigation on the implications of behavioral economics for financial literacy and public policy. Altman summarized and highlighted various techniques to behavioral economics in the context of the conventional economic wisdom and the implications of these various methods for financial literacy, related institutional change, and public policy. Conventional economics stated no substantive improvement from improvements to financial literacy. The errors and biases method to behavioral economics recommended limited improvements to decision making from financial education as errors and biases were hardwired in the brain. Government and expert intervention influencing individual choice behavior was recommended. The evidence also recommended that the bounded rationality method to behavioral economics, with its concentration on smart decision makers and the importance institutional and environment constraints on decision making, was the most promising focus through which to analyze financial decision making. Therefore, financial decision making could be improved by providing decision makers with better quality information presented in a non-complex fashion, an institutional environment conducive to better decisions, an incentive structure, which internalize externalities involved in financial decision making, and financial education, which would facilitate making the best implementation of the information at hand within a specific decision-making environment.

\section{The proposed study}


This paper presents an empirical investigation to study the effects of financial management skills, wealth and financial intelligence on investors' risk tolerance among some randomly chosen investors who were active on TSE market in city of Esfahan, Iran. The sample study is determined as follows,

$N=Z_{\alpha / 2}^{2} \frac{p \times q}{e^{2}}$,

where $N$ is the sample size, $p=1-q$ represents the probability, $z_{\alpha / 2}$ is CDF of normal distribution and finally $\varepsilon$ is the error term. For our study we assume $p=0.5, z_{\alpha / 2}=1.96$ and $e=0.05$, the number of sample size is calculated as $N=384$. The proposed study has designed a questionnaire in Likert scale (1-5) and Table 1 shows details of some basic statistics along with Kolmogorov-Simrnov test.

\section{Table 1}

The summary of questions of the survey

\begin{tabular}{lccccc}
\hline Variable & Questions & Mean & Standard & Variance & KZ Sig. \\
\hline Financial intelligence & $1-14$ & 3.6233 & 0.7337 & 0.538 & 0.08 \\
Wealth & $15-24$ & 3.6738 & 0.7026 & 0.494 & 0.07 \\
Financial management skills & $25-38$ & 3.7391 & 0.6424 & 0.413 & 0.23 \\
Financial risk tolerance & $39-49$ & 3.8294 & 0.6296 & 0.396 & 0.09 \\
\hline
\end{tabular}

As we can observe from the results of Table 1, all variables of the survey follow normal distribution when the level of significance is five percent. The main hypothesis of the survey investigates whether investors' personal characteristics influence on their risk tolerance or not. There are also three subhypotheses associated with the proposed study of this paper as follows,

1. Investors' financial intelligence influences positively on their financial risk tolerance.

2. Investors' wealth influences positively on their financial risk tolerance.

3. Investors' financial management skills influence positively on their financial risk tolerance.

The study uses simple regression model as well as structural equation modeling to verify the main hypothesis as well as three sub-hypotheses of the survey.

\section{The results}

In this section, we present details of our findings on testing various hypotheses of the survey.

\subsection{The main hypothesis: The effects of personal characteristics}

The main hypothesis of the survey investigates the effects of investors' personal characteristics on financial risk tolerance. Table 2 shows details of our regression analysis.

\section{Table 2}

The summary of regression analysis

\begin{tabular}{lccccc} 
& \multicolumn{3}{c}{ Non-standard $\beta$} & Standard $\beta$ & \\
& $\beta$ & Error & $\beta$ & t-value & Sig. \\
\hline Intercept & .847 & .109 & & .7917 & .001 \\
Personal characteristics & .611 & .029 & .618 & .83427 & .001 \\
\hline $\mathrm{R}^{2}=0.669$ & & & &
\end{tabular}

As we can observe from the results of Table 2, there is a meaningful and positive relationship between investors' personal characteristics and their financial risk tolerance. Therefore, the main hypothesis of the survey has been confirmed. 


\subsubsection{The effects of financial intelligence on financial risk tolerance}

The first sub-hypothesis of the survey is associated with the relationship between investors' financial intelligence and their financial risk tolerance. Table 3 shows details of our findings.

Table 3

The summary of regression analysis for the first hypothesis

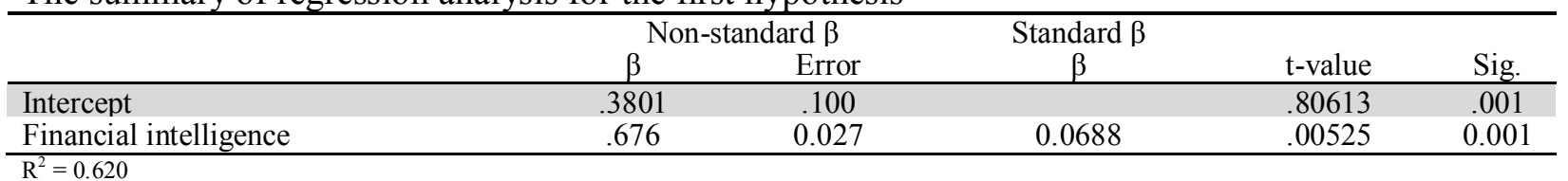

As we can observe from the results of Table 3, there is a meaningful and positive relationship between investors' financial intelligence and their financial risk tolerance. Therefore, the first subhypothesis of the survey has been approved.

\subsubsection{The effects of investors' wealth on financial risk tolerance}

The second sub-hypothesis of the survey is associated with the relationship between investors' wealth and their financial risk tolerance. Table 4 shows details of our results.

Table 4

The summary of regression analysis for the second hypothesis

\begin{tabular}{lccccc} 
& \multicolumn{2}{c}{ Non-standard $\beta$} & Standard $\beta$ & t-value & Sig. \\
\hline Intercept & $\beta$ & Error & $\beta$ & .32812 & .001 \\
Wealth & .4811 & .120 & & .513 & .89119 \\
\hline $\mathrm{R}^{2}=0.506$ & .439 & .032 & .001 \\
\hline
\end{tabular}

As we can observe from the results of Table 4, there is a meaningful and positive relationship between investors' wealth and their financial risk tolerance. Therefore, the second sub-hypothesis of the survey has been approved.

\subsubsection{The effects of investors' financial management skills on financial risk tolerance}

The third sub-hypothesis of the survey is associated with the relationship between investors' financial management skills and their financial risk tolerance. Table 5 shows details of our results.

Table 5

The summary of regression analysis for the third hypothesis

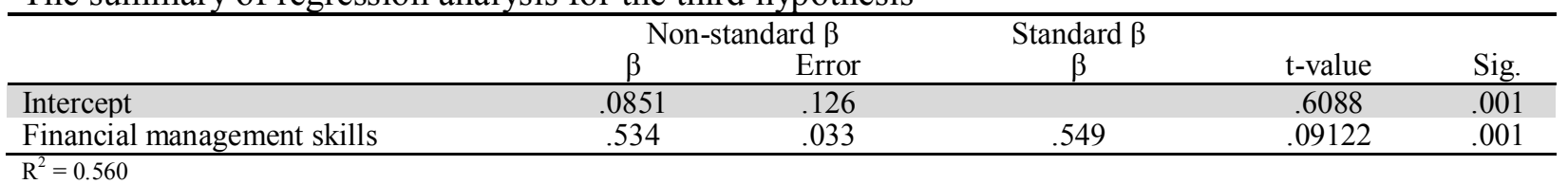

As we can observe from the results of Table 5, there is a meaningful and positive relationship between investors' financial management skills and their financial risk tolerance. Therefore, the third sub-hypothesis of the survey has been approved.

\subsection{Structural equation modeling}

The proposed study of this paper has also performed structural equation modeling to examine the effects of different factors on financial risk tolerance and Fig. 1 shows details of our survey. As we 
can observe from the results of Fig. 1, all t-student values are within acceptable limit when the level of significance is five percent. The Root Mean Square Error of Approximation (RMSEA) is equal to 0.047 , which is well below the acceptable limit of 0.09. Based on the results of SEM implementation, financial intelligence, wealth and financial skills influence positively on financial risk tolerance.

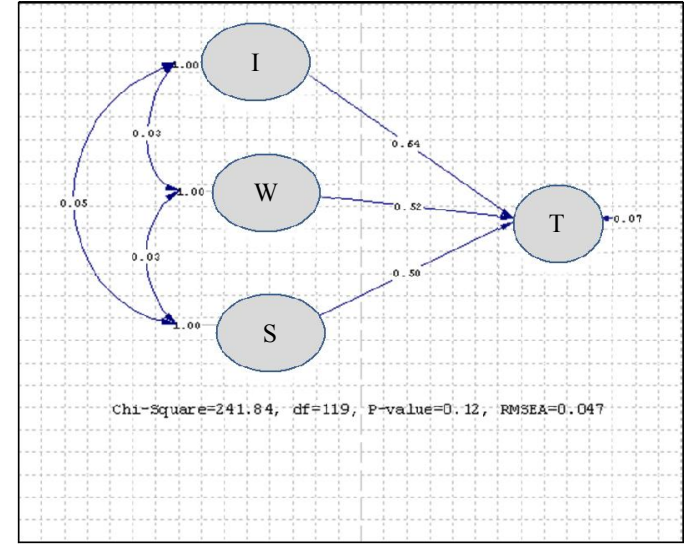

The results of standard coefficients on risk tolerance

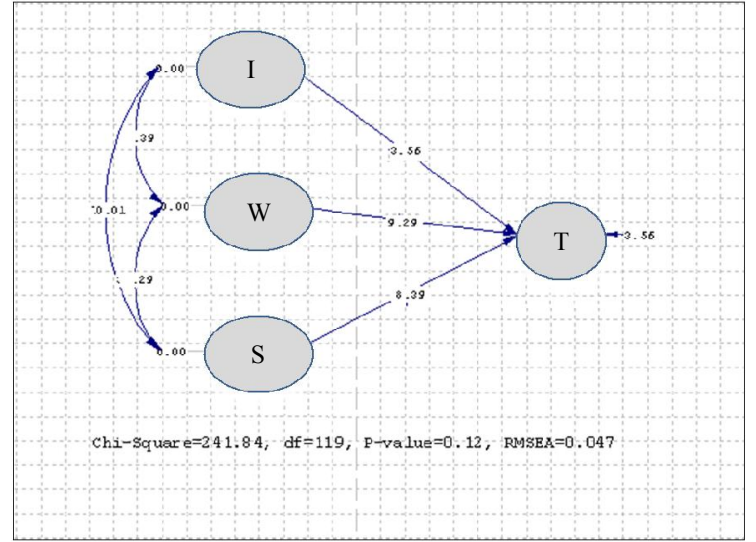

The results of t-student values on risk tolerance

Fig. 1. The results of structural equation modeling (SEM)

\section{Conclusion}

In this paper, we have presented an empirical investigation to study the effects of investors' personal characteristics including financial intelligence, wealth and financial skills influence on financial risk tolerance. The results of simple regression analysis as well as structural equation modeling have confirmed that these components influence on investors' financial risk tolerance, positively. In addition, the study has applied structural equation modeling and the results are consistent with the findings of regression analysis.

\section{Acknowledgement}

The authors would like to thank the anonymous referees for constructive comments on earlier version of this paper.

\section{References}

Altman, M. (2012). Implications of behavioural economics for financial literacy and public policy. The Journal of Socio-Economics, 41(5), 677-690.

Chorafas, D. N. (2011). Wealth Management: Private Banking, Investment Decisions, and Structured Financial Products. Butterworth-Heinemann.

Durrani, N., \& Tariq, V. N. (2012). The role of numeracy skills in graduate employability. Education+ Training, 54(5), 419-434.

Finke, M. S., \& Huston, S. J. (2003). The brighter side of financial risk: Financial risk tolerance and wealth. Journal of Family and Economic Issues,24(3), 233-256.

Lusardi, A., van Rooij, M., \& Alessie, R. (2007). Financial Literacy and Stock Market Participation (No. wp162).

Millo, Y., \& MacKenzie, D. (2009). The usefulness of inaccurate models: Towards an understanding of the emergence of financial risk management. Accounting, Organizations and Society, 34(5), 638-653.

Pham, T. H., Yap, K., \& Dowling, N. A. (2012). The impact of financial management practices and 
financial attitudes on the relationship between materialism and compulsive buying. Journal of Economic Psychology, 33(3), 461-470.

Van Rooij, M., Lusardi, A., \& Alessie, R. (2007). Financial literacy and stock market participation (No. w13565). National Bureau of Economic Research.

Van Rooij, M., Lusardi, A., \& Alessie, R. (2011). Financial literacy and stock market participation. Journal of Financial Economics, 101(2), 449-472.

Yao, R., \& Curl, A. L. (2011). Do market returns influence risk tolerance? Evidence from panel data. Journal of Family and Economic Issues, 32(3), 532-544.

Yao, R., Sharpe, D. L., \& Wang, F. (2011). Decomposing the age effect on risk tolerance. The Journal of Socio-Economics, 40(6), 879-887. 